\title{
Preschool vision screening
}

\author{
S N Jarvis, R C Tamhne, L Thompson, P M Francis, J Anderson, A F Colver
}

\begin{abstract}
Although a good case for preschool screening for vision defects can be made there is very little evidence that existing programmes are effective in practice. A comparative trial of three different methods of preschool vision screening is described. Some 7000 children initially aged 5 months (younger cohorts) and 30 months (older cohorts) in three matched areas entered the trial during 1987. During 18 months of follow up new visual and ocular defects among these children were ascertained through ophthalmology outpatients and from optician records.

Screening at 35 months by an orthoptist based in the community is superior to conventional health visitor surveillance at $\mathbf{3 0}$ months and to an agreed programme of primary care screening for squint at $30-36$ months as judged by screening sensitivity $(100 \% v 50 \% v$ $50 \%$ ) and the incidence of treated target conditions (17 $v 3 v 5$ per 1000 person years). A notable feature in the area served by the orthoptist is that 13 children received treatment for straight eyed visual acuity loss from among 1000 children whereas there were no such cases among 2500 in the comparison areas.

In the younger cohorts (that is, screening at age 5-9 months) all three programmes showed equally poor results, only one of the eight treated target conditions arising from all $\mathbf{3 5 0 0}$ younger children being screen detected.
\end{abstract}

The early detection of squints, refractive errors, and amblyopia in childhood is desirable because of the critical requirement for a clear retinal image in the normal development of visual physiology. ${ }^{1}$ In England and Wales $98 \%$ of all health authorities conduct preschool vision screening with the intention of early detection of such abnormalities, but do these programmes have the desired effect? ${ }^{2}$

The primary requirements for a screening programme are met, ${ }^{3}$ insofar as vision and ocular defects represent common and serious disorders (affecting more than $2 \%$ of children by age 2$),{ }^{4}$ which have at least partly understood natural histories ${ }^{56}$ (including recognisable preclinical phases). There is also circumstantial evidence that early treatment of these disorders will produce benefit in terms of a reduced frequency and severity of permanent amblyopia. ${ }^{78}$ There must still be doubts, however, about these benefits of early treatment in view of the excellent study of Ingram et al, which was unable to demonstrate any benefit from the use of glasses in children with severe refractive errors between the ages of 1-3 years. ${ }^{9}$

Is there then any evidence that preschool vision screening programmes are effective in practice? Encouraging results have been reported from trials of community screening by photorefraction ${ }^{8}$ and by orthoptists. ${ }^{10} \mathrm{~A}$ retrospective cohort study in Canada also suggested a reduction in poor vision outcomes of $50 \%$ after preschool vision screening using the 'illiterate $\mathrm{E}$ test'. ${ }^{11}$ On the other hand, an evaulation in 1980 of a community programme relying on clinical medical officers, health visitors, and general practitioners, similar to that used throughout England and Wales, suggested that such preschool vision screening had virtually no effect on the diagnostic process. ${ }^{12}$ There was also evidence in 1984 that $30 \%$ or more of important squints and refractive errors remained undetected until after the age of 5 years in a similar programme in Newcastle. ${ }^{13}$ Recently Ingram reviewed the evidence and concluded that a 'screening programme at the age of 3.5 years was 'no more effective' than school screening 'in producing better results'. ${ }^{14}$

The issue is of particular relevance now, first because the Hall report has recommended that 'screening for vision defects in preschool children should be confined to history and observation', ${ }^{15}$ second because of the movement of preschool surveillance away from health authority clinics to primary care, and third because of the competing claims of orthoptists ${ }^{10}$ and opticians (through a national advertising campaign) to take on elements of this screening role.

A decision to pilot preschool vision screening at age 5 and 35 months by a community orthoptist in part of Newcastle upon Tyne (leaving the remainder of Newcastle with conventional clinical medical officer/health visitor/general practitioner screening) coincided with the implementation across the whole of adjacent Northumberland Health District of an agreed minimum set of screening procedures centred in primary care that included squint checks at 7-9 and 3036 months. ${ }^{16}$ There was therefore the opportunity for a comparative evaluation of three different preschool vision screening programmes on a prospective basis (the orthoptist pilot, the existing programme in Newcastle, and the new Northumberland procedures). This paper is a report of this evaluation after 18 months of follow up.

\section{Methods}

The objective was to compare the three prog- 
rammes in terms of (i) the rate of screening coverage of the population for which it was intended, (ii) the rate and timing of target condition identification in the whole population irrespective of the source of referral, and (iii) the performance characteristics of the screening tests among those who attended for screening (that is, sensitivity, specificity, and predictive value).

The target conditions for preschool vision screening were taken to be squints, and/or visual acuity loss (which might be due to refractive error or to amblyopia) confirmed by an ophthalmologist. Two definitions of a correct target condition were used for analysis: (i) the presence of a target condition newly confirmed by an ophthalmologist after the age of entry to a cohort or (ii) such a target condition where there was at least a prescription of treatment (including refractive correction, orthoptic exercises, or patching). False positives will thus include all screening referrals to outpatients that do not satisfy the particular 'correct' definition in use (for example, non-target conditions, or children given repeat appointments for 'observation').

\section{SAMPLE}

The orthoptist pilot area in Newcastle had been predetermined, and therefore the two comparison areas were selected (from wards in the remainder of Newcastle and in Northumberland) to have equal numbers of children, to have similar deprivation indices, ${ }^{17}$ and to form part of the catchment of the same hospital ophthalmological services.

All children resident in these areas and who became 5 months or 30 months of age in 1987 were recruited at these ages into the study cohorts producing six groups with about 1000 children in each (three younger and three older cohorts).

The vision screening procedures and their timing for these six cohorts are shown in table 1.
Two sets of data were collected about these children: the first about screening and the second about target conditions.

\section{SCREENING DATA}

For each cohort child the community child health clinic record (the MCW46) was examined to establish whether screening had occurred and to note any relevant referral data. Additional material was extracted from the routine quarterly returns made by the orthoptist for the pilot areas and this included data about children called for review after attending screening as well as those seen by the community orthoptist at the request of primary care teams.

To establish the extent to which population screening was actually practised by opticians, the item of service claim forms GOS(ST) and GOS(V), which are held by the family practitioner committees, were searched (ST $=$ free sight test, $\mathrm{V}=$ exempt prescription).

\section{TARGET CONDITION DATA}

Two hospital ophthalmology departments in Newcastle serve the whole study population. The eight consultant ophthalmologists and administrative staff established a temporary system of individual returns for preschool children attending outpatient appointments. Additional sources of target condition cases were the MCW46 and orthoptist clinic records: any notes of eye referrals or references to eye conditions were followed up by a search of hospital records. From these sources, children who were members of the cohorts and who had been first referred after the age of 5 or 30 months were identified. The case material was later enhanced by direct scrutiny of casenotes to arrive at a preliminary diagnostic classification (see results). A final diagnosis for all cases will eventually be determined at the end of the follow up period after discussion with the ophthalmologists concerned.

Table 1 Timing and content of screening in the three areas

\begin{tabular}{|c|c|c|c|}
\hline Area & Younger cohort & Older cohort & Place and personnel \\
\hline $\begin{array}{l}\text { Northumberland } \\
\text { comparison* }\end{array}$ & At $7-9$ months: squint check & At $30-36$ months: squint check $f$ & $\begin{array}{l}\text { Local arrangement by health } \\
\text { visitors, general practitioners, } \\
\text { clinical medical officers }\end{array}$ \\
\hline Orthoptist & $\begin{array}{l}\text { At } 5 \text { months: history and } \\
\text { observation, cover tests, ocular } \\
\text { movements, } 20 \text { diopter base } \\
\text { out prism tests, convergence }\end{array}$ & $\begin{array}{l}\text { At } 35 \text { months: as at } 5 \text { months+ } \\
\text { acuity tests (Sheridan Gardner } \\
\text { letter matching or Kaye } \\
\text { picture tests) }\end{array}$ & $\begin{array}{l}\text { By invitation }(\times 2) \text { to community } \\
\text { orthoptist in local clinic }\end{array}$ \\
\hline $\begin{array}{l}\text { Newcastle } \\
\text { comparison } \oint\end{array}$ & $\begin{array}{l}\text { At } 9 \text { months: standard check, } \\
\text { 'doubt about infant or } \\
\text { personal/family history of } \\
\text { squint' }\end{array}$ & $\begin{array}{l}\text { At } 30 \text { months: standard check, } \\
\text { 'pick up a thread' }\end{array}$ & $\begin{array}{l}\text { By home visit from health } \\
\text { visitor }\end{array}$ \\
\hline
\end{tabular}

* Squint check also at 18 months.

†'Always ask parents if they have noticed a squint, then look for obvious squint and look for symmetry of corneal reflections for far and near vision'.

¥Superimposed on the Newcastle system (see comparison area).

SOther opportunities for universal vision surveillance also occur during the 6 and 18 month health visitor checks. These records are not kept in the MCW46 record however.

Table 2 Coverage of screening in the three areas

\begin{tabular}{|c|c|c|c|c|c|c|}
\hline & \multicolumn{3}{|c|}{ Younger cohort } & \multicolumn{3}{|c|}{ Older cohort } \\
\hline & Size & Records seen & Coverage $^{*}(\%)$ & Size & Records seen & Coverage* $(\%)$ \\
\hline $\begin{array}{l}\text { Northumberland comparison area (health } \\
\text { visitors and general practitioners) } \\
\text { Newcastle orthoptist area (orthoptist) } \\
\text { Newcastle comparison area (health visitor) }\end{array}$ & $\begin{array}{l}1066 \\
1050 \\
1410\end{array}$ & $\begin{array}{r}903 \\
1050 \\
1321\end{array}$ & $\begin{array}{l}61 \\
71 \\
81\end{array}$ & $\begin{array}{l}1151 \\
1026 \\
1380\end{array}$ & $\begin{array}{r}967 \\
1026 \\
1259\end{array}$ & $\begin{array}{l}84 \\
60 \\
59\end{array}$ \\
\hline
\end{tabular}

${ }^{*}$ As a proportion of records seen. 
The source of referral for each potential case seen in outpatients was determined from outpatient notes, MCW46 and orthoptist records, and where in doubt by direct inquiry from that child's health visitor. Such referral was attributed to screening only if there was evidence that it resulted from routine surveillance initiated by a professional at the appropriate age (that is, was preclinical).

\section{Results}

\section{SCREENING DATA}

Altogether $8600 \mathrm{MCW} 46$ and orthoptist records were examined in some 24 clinics distributed across Newcastle and Northumberland. These represented $93 \%$ of the target populations in the different cohorts.

From the data extracted (table 2) it is seen that the coverage rates of $60-70 \%$ achieved by the orthoptist are similar to rates achieved in the comparison areas. The exceptions to this are the coverage rates of over $80 \%$ achieved by Newcastle health visitors for their examination of infants aged 9 months and by the Northumberland primary care teams for their examinations of children at 2.5-3 years of age.

A substantial proportion of those who

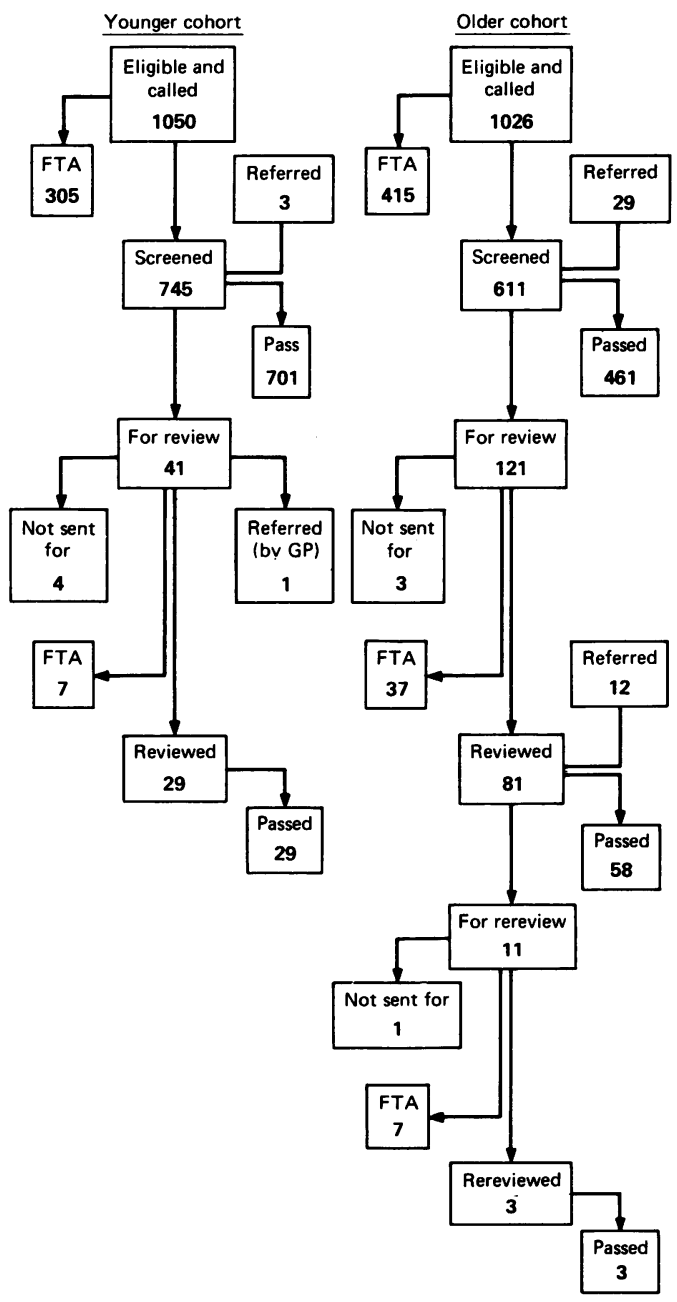

Figure 1 Process of screening by the orthoptist (from orthoptist records). FTA, failed to attend; GP, general practitioner. attended for screening by orthoptists were asked to come again for review rather than being definitively assigned as positive or negative (6\% of the younger cohort and $20 \%$ of the older cohort). Figure 1 shows that about one third of those called for review failed to attend. Furthermore the referral rate from those who are reviewed was at least three times higher than the primary screening referral rate. This raises the possibility of a substantial number of children who were screened once, and who might have needed referral but who failed to attend for review by the orthoptist. We have no equivalent data from the comparison areas.

\section{OPTICIAN SCREENING AND CASES}

A preliminary search of Northumberland* opticians' returns GOS(V) and GOS (ST) for one quarter of the follow up period (84000 forms undifferentiated by age) showed only 16 cohort members who had received free sight tests but did identify three new children prescribed glasses. Opticians therefore hardly 'screened' this population of children, but they were seeing a number of cohort members with target conditions. These cases are 'treated' by opticians and may never come to the attention of hospital based eye services.

\section{TARGET CONDITION DATA}

A total of 138 potential cases of target conditions have so far been identified from the records of cohort members attending ophthalmology outpatients. These children were the 'incident' cases who were first referred after entry into the cohorts at age 5 and 30 months respectively. The ascertainment system also identified a large number of 'prevalent' cases in these cohorts (that is, children who had already been diagnosed with target conditions before entry into the cohort). A preliminary diagnostic assignment of the incident cases (fig 2) showed little difference between the three programmes for the younger cohorts but a striking difference in favour of the orthoptist programme for the older cohorts.

When comparing the number of cases arriving from areas with differing screening programmes, it should be recalled that the Newcastle comparison cohorts are up to $35 \%$ larger than the other cohorts (see table 2). This makes even more striking the excess of target conditions (both total and treated) arising from the older cohort in the orthoptist area $\left(\chi^{2}=42 \cdot 0\right.$ and $24 \cdot 3, \mathrm{df}=2, \mathrm{p}<0.001$ ). Moreover, of the 26 older children with treated target conditions from the orthoptist area, half had straight eyed visual acuity loss $\dagger$ whereas no similar children have yet appeared from the comparison areas.

When considered from the perspective of the ophthalmologists the actual proportions of new

*Newcastle (rather than Northumberland) opticians served the majority of the cohorts.

†Virtually all of these children had refractive errors and most were thought to be amblyopic. However the determination of amblyopia at this age is difficult.' 

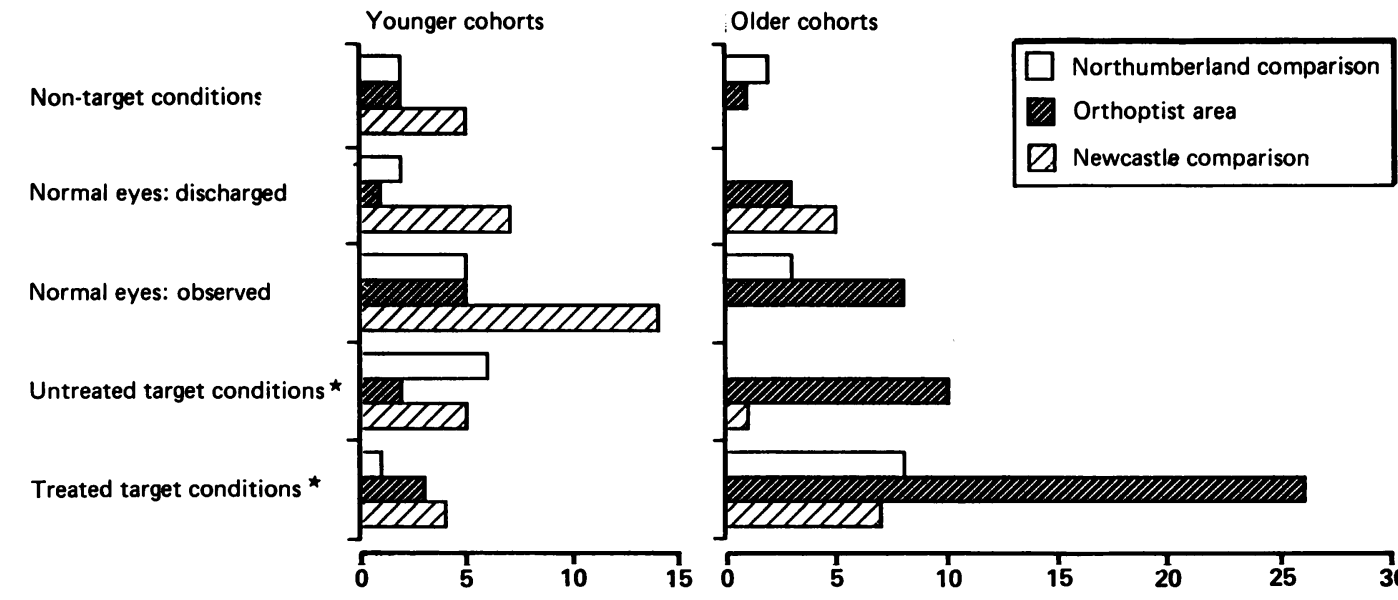

Figure 2 Diagnoses of children from the three areas seen as new outpatients by ophthalmologists. ${ }^{\star}$ Squint, and/or visual acuity loss confirmed by an ophthalmologist.
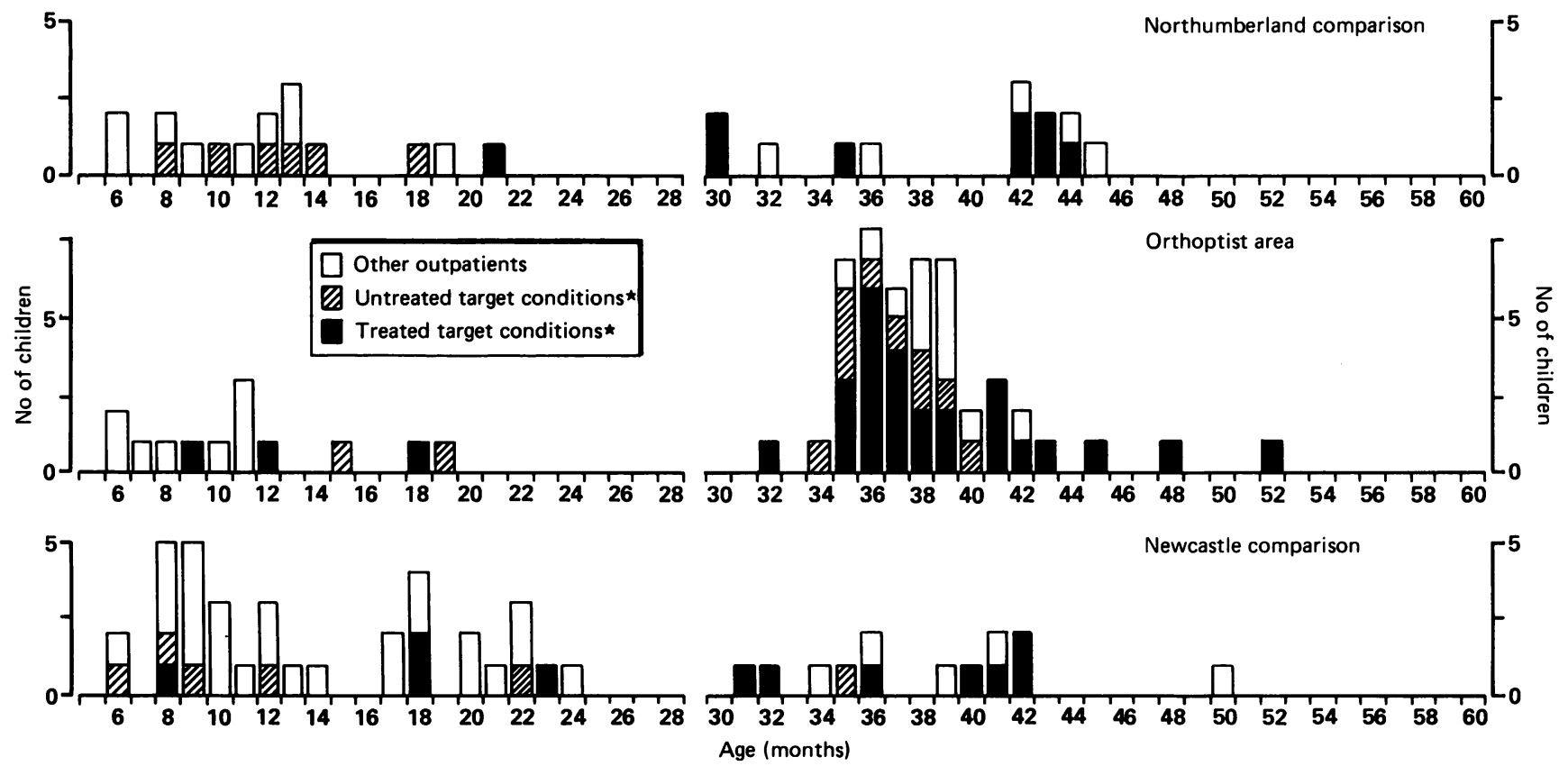

Figure 3 Age of children from the three areas when first seen as outpatients by ophthalmologists. ${ }^{\star}$ Cases of squint and/or visual acuity loss confirmed by an ophthalmologist.

outpatients appearing from the cohorts with 'correct' target conditions was appreciably different in the two age groups. Thus only a third of the children seen as outpatients from the younger cohort were actually diagnosed by the ophthalmologist as having a target condition and less than half of them in turn had entered treatment. On the other hand, for older cohort children, two thirds of new outpatients had the target conditions, of whom over three quarters entered treatment. It was also interesting to note among the younger cohort children seen in outpatients the relatively large number with 'normal eyes but to be observed'. It appeared that once a child under 1 year of age had been referred, some ophthalmologists were unlikely to discharge them as normal preferring to review them when they were older. This group should contract as follow up proceeds but meanwhile represent a substantial load on outpatients as well as potential anxiety to parents and children.
When the timing of the diagnosis of these outpatient cases was considered (fig 3) it was seen that although there was no significant difference in the mean age at diagnosis, there was a considerable surge of children with the target conditions of vision screening in the few months after orthopist screening at 35 months. This increase in cases was largely composed of children who went on to receive treatment.

\section{CHARACTERISTICS OF THE SCREENING TESTS}

Table 3 shows the routine health visitor contacts at 9 and $\mathbf{3 0}$ months in the Newcastle comparison area compared in more detail with screening by the orthoptist at 5 and 35 monthsł. It was clear that vision screening in the younger age group

\footnotetext{
¥There was insufficient data on the original source of Northumberland cases to use them in such an analysis. Howeve it was clear that at least four of the eight treated target conditions in the older Northumberland cohort were false negatives at screening.
} 
Table 3 Performance characteristics of preschool vision screening where correct $=(a)$ any target condition and $(b)=$ treated target conditions only (numerator/denominator)

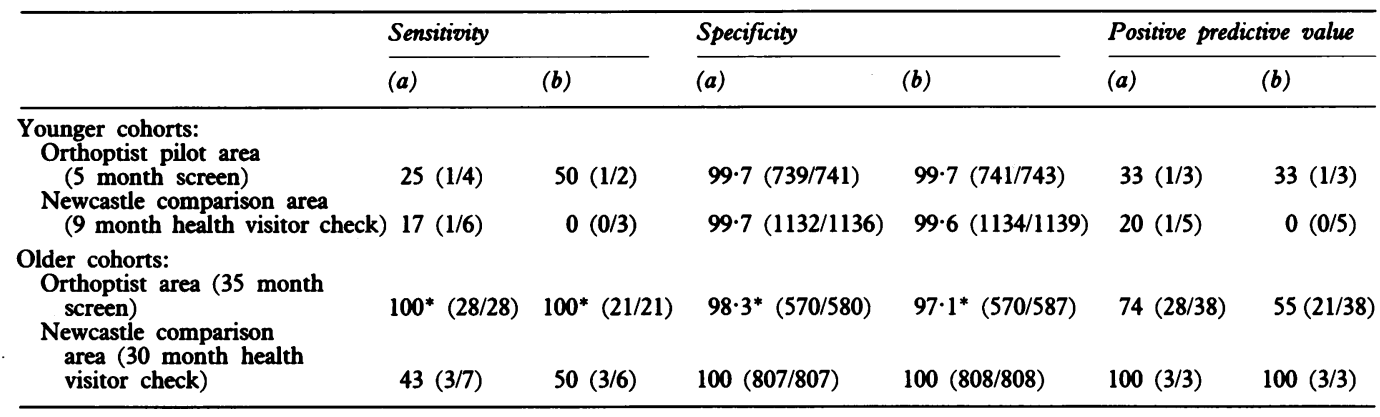

*Fisher exact two tailed probabilities of difference between orthoptist and comparison $\leqslant 0 \cdot 01$.

missed many of the target conditions irrespective of which programme does the screening. Meanwhile, false positive referrals from screening at 5-9 months were rare and no worse for the health visitors than for the orthoptists.

In the older cohort on the other hand no false negative cases have been detected so far after orthoptist screening at 35 months. Indeed three quarters of the 26 older children seen in outpatients with treated target conditions were referred from orthoptist screening. This sensitivity was perhaps at the expense of a slight lack of specificity (that is, increased false positive rate), though a positive predictive value of $74 \%$ must be considered good. By contrast, Newcastle health visitor surveillance at 30 months although very specific (that is, no false positives), missed over half of the small number of cases that have so far appeared in the screened part of this cohort.

\section{Discussion}

We present strong preliminary evidence for a beneficial effect from community orthoptist screening at age 35 months when compared with conventional health visitor surveillance or to specific attempts to detect squints in primary care. This finding has led to the adoption of such screening across the whole of Newcastle Health Authority.

By contrast we also present preliminary evidence for a lack of any beneficial effect of community orthoptist screening at 5 months of age. This practice has now been discontinued in Newcastle. The community orthoptist is still available to see children referred to her from this younger age group and will thus hopefully reduce the load of outpatient referrals from primary care.

There are some important reservations to be made concerning these conclusions. First the follow up is not yet complete. Further false negative cases may continue to appear in the screened cohorts but this would now seem to be unlikely to change the conclusion regarding relative screening sensitivity. However there is also the important question of the ultimate outcome of early treatment. The planned follow up of the cohorts extends for 2.5 years after their original recruitment (that is, until the age of 35 months and 60 months respectively) and as they reach these 'exit' ages the children become eligible for rescreening either by orthoptists (New- castle younger cohort), by primary care teams (Northumberland younger cohort), or at school entry (Newcastle and Northumberland older cohorts). These occasions will be used as final opportunities to check the vision of the cohort children particularly in terms of amblyopia (that is, deficiency in visual acuity uncorrectable by refraction). It is only a demonstration of differences in the rates of amblyopic children between cohorts that will refute the proposition that all the treated target conditions in the older orthoptist cohort would have managed just as well with later (or no) treatment.

A second reservation is that the children presenting in eye outpatient clinics may not represent all the referred children for a number of reasons. For instance, when looking at the outpatient referrals arising from the different areas one must bear in mind the 'clinical' service offered by the orthoptist to local health professionals requiring an opinion on children of any age. This might have had two effects. Potential cohort children could have been seen by the orthoptist before the entry ages at 5 or 30 months and thus have compromised the original comparability of the cohorts (actually six visits with one onward referral). Alternatively this request service might have lowered the proportion of inaccurate outpatient referrals in the orthoptist area after the entry ages (84 visits with six older onward referrals). Not only does it seem therefore that the referral threshold for such an orthoptist opinion is low, but it also seems that a number of unnecessary outpatient referrals are avoided by this means. This may partly explain the excess of normal eyes and non-target conditions referred to outpatients from the younger cohort in the Newcastle comparison area where such a service was not available (fig 2).

A third qualification is that other potential outpatients in eye clinics may have been directed or self referred to opticians and may even have received treatment of refractive errors (one of the target conditions) entirely outwith the hospital service. We will ascertain such cases more completely towards the end of the follow up period by questionnaire to the families of cohort children. Meanwhile our pilot search of records from the family practitioner committees suggests that there are a number of such children but that because of the large numbers of such records this is an impractical source. 
The final qualification to the outpatient data is that there are some children who are referred but never appear in outpatients. Of a total of 44 referrals from orthoptist screening (see fig 1) three have not been traced as outpatients. We have no equivalent data so far on screening referrals from the comparison areas.

\section{PREVIOUS EVALUATIONS OF PRESCHOOL VISION SCREENING}

The only similar comparative evaluation which we have been able to find in the literature is that done by Edwards et al of community orthoptist screening at age $3.5-4$ years. ${ }^{10}$ The preliminary findings from our study confirm their reports that community orthoptist screening can achieve high coverage rates and result in relatively large numbers of accurate referrals when compared with screening by health visitors. In their study two cohorts of some $\mathbf{3 0 0 0}$ children each were screened and followed up by them for two years. As a comparison group, the second cohort was composed of children in an adjacent part of the health district where health visitors were trained in orthoptic techniques. For some reason only about 1000 of these children were followed through in the study. It is also unclear whether the original populations were similar in sociodemographic mix - an important issue in studying the uptake of screening tests. The main differences from our study are that our older cohort was screened at age 35 months rather than 42-48 months and that we have attempted to use as comparison groups two conventional models of preschool screening (that is, health visitor surveillance and primary care squint screening).

A further relevant and important study of vision screening among older preschool children is that by Ingram and his colleagues, ${ }^{18}$ in which some 1500 children were screened at age 3.5 years by both orthoptists (cover and visual acuity tests) and then independently by an ophthalmologist (refraction). Between 1973 and 1978 they achieved screening coverage rates of over $70 \%$-that is, some $10 \%$ higher than those achieved in our study. Their overall yield of new detected cases at screening was similar at $4.9 \%(74 / 1507)$ compared with $4 \cdot 6 \%(28 / 611)$ by the orthoptist in our study.

Beyond this, comparison is difficult, as their study does not have a separate cohort by which one might eventually judge the effect of earlier diagnosis as a result of screening. Rather Ingram appears to have now concluded that as many of the more serious visual abnormalities had presented (or could be detected by screening) at earlier ages and as there was already evidence that refractive correction started at 1 year of age did not work, ${ }^{9}$ then screening at 3.5 years was unlikely to have a beneficial effect. ${ }^{14}$ However, one might equally conclude that screening at 3.5 years found a new and larger group of children with milder abnormalities that might have a different natural history from severe hypermetropia and which respond better to treatment.

With respect to the younger cohorts there is little to refer to in the literature. The Cambridge trial of photorefraction at 6-9 months does not attempt to compare this with other methods of younger preschool vision screening, but is rather concerned to demonstrate the efficacy of early treatment by controlled trial. ${ }^{8}$ Their screening coverage rates at $71 \%$ are remarkably similar to ours (see table 2) and the yield in terms of squints detected at screening was also comparable.

PRACTICAL IMPLICATIONS FOR THE EVALUATION OF SCREENING

There are two further issues in the evaluation and monitoring of screening that are highlighted by this study.

The detection of preclinical conditions requires that the population who are to enter a screening programme should not have already presented clinically. We have restricted entry in the present study to children who have not been previously referred to eye outpatient clinics or prescribed glasses by opticians. In some studies, however, this distinction is not clearly made. ${ }^{4}$ Equally, prior parental suspicion of abnormality should not serve to exclude children from a screening evaluation. ${ }^{13}$ On the contrary, screening invitations may systematically attract such preclinical high risk clients. Some screening programmes deliberately set out to heighten parental awareness, effectively using parents as screeners. ${ }^{19}$ In this context, what distinguishes a screening programme we believe is the delivery of a standard intervention to whole populations of healthy people with the intention of accelerating diagnosis.

At their worst, screening programmes will have a number of disadvantages ('disbenefits'). ${ }^{20}$ For instance the programme may: (a) not be used by a minority at high risk, (b) lead to the referral of (and anxiety in) a large proportion of false positives, (c) falsely reassure a number of true positives (that is, false negatives), and (d) identify a group at high risk (for example, screen positives or 'uncertain, called for review') who are subsequently lost to follow up.

In the present study there is evidence that such disadvantages do exist in vision screening. Although there is no obvious concentration of risk in any of the unscreened populations, there is a minor false positive problem albeit confined to the very sensitive screening conducted by the orthoptist among older children. There are also a number of false negatives among the younger groups and those screened by health visitors. Lastly there is a small loss to follow up of high risk groups both after primary screening and after referral. Definitive conclusions concerning the disadvantages (a) and (c) above must await the completion of the follow up period but one might reasonably conclude that preschool vision screening by community based orthoptists at the age of 35 months leads to earlier diagnosis and treatment without important side effects.

We gratefully acknowledge the assistance and encouragement of Newcastle consultant ophthalmologists, the staff of the hospital outpatients and eye departments and of the community health staff throughout Newcastle and Northumberland. We also thank the local ophthalmic committees in Newcastle and Northumber- 
land for permission to examine their records. This research is supported by a grant from the locally organised research scheme of Newcastle Health Authority.

1 Moses RA, Hart WM, eds. Adler's physiology of the eye. 8th Ed. St Louis: Mosby, 1987:682.

2 Stewart-Brown SL, Haslum MN, Howlett B. Preschool vision screening: a service in need of rationalisation. Arch vision screening: a service
Dis Child 1988;63:356-9.

3 Wilson JMG, Jungner G. Principles and practices of screening for disease. Geneva: WHO, 1968. (Public Health Paper No 34.)

4 Johnson A, Stayle $M$, Wortham C. Vision screening at 8 and 18 months. BMF 1989;299:545-9.

5 Von Noorden GK. Amblyopia: basic concepts and current treatment. Proceedings of symposium on strabismus. Fournal of the New Orleans Academy of Ophthalmology 1978: $1-13$.

6 Ingram RM. The possibility of preventing amblyopia. Lancet 1980;i:485-7.

7 Fielder AR. The management of squint. Arch Dis Child 1989; 64:413-8.

8 Atkinson J, Braddick O, Wattam-Bell J, Durden K, Bobier W, Pointer J. Photorefractive screening of infants and W, Pointer J. Photorefractive screening of infants and
effects of refractive correction. Invest Ophthalmol Vis Sci (Suppl) 1987;28:399.
9 Ingram RM, Walker C, Wilson JM, et al. A first attempt to prevent amblyopia and squint by spectacle correction of abnormal refractions from age of 1 year. Br $\mathcal{F}$ Ophthalmol 1985;69:851-3.

10 Edwards RS, Whitelaw AJ, Abbott AG. Orthoptists as preschool screeners: a two year study. British Orthoptic School screeners: a

11 Johnson AM. Visual problems in children: detection and referral. $\mathcal{F} R$ Coll Gen Pract 1984;34:32-5.

12 Feldman WM, Milner RA, Sackett B, et al. Effects on preschool screening for vision and hearing on prevalence of vision and hearing problems 6-12 months later. Lancet 1980;ii:1014-6.

13 Hall SM, Pugh AG, Hall DMB. Vision screening in the under 5s. $B M \mathcal{F}$ 1982;285:1096-8.

14 Ingram RM. Amblyopia. BMF 1989;298:204.

5 Hall DMB, ed. Health for all children. Oxford: Oxford University Press, 1989.

16 Colver AF, Steiner H. Health surveillance of preschool children. BMf 1986;293:258-60.

17 Townsend $\mathrm{P}$, Phillimore $\mathrm{P}$, Beattie A. Health and deprivation: inequality and the north. London: Croom Helm, 1988.

18 Ingram RM, Holland WW, Walker C, Wilson JM, Arnold PE. Screening for visual defects in preschoolchildren. $\mathrm{Br}$ f Ophthalmol 1986;70:16-21.

19 Hitchings V, Haggard MP. Incorporation of parental suspicions in screening infants. Br 7 Audiol 1983;17:71-5.

20 Wakefield J. Seek wisely to prevent. London: HMSO, 1972.

Haemorrhagic shock and encephalopathy syndrome

There seems to have been little advance in the basic understanding of this syndrome since it was first described from the Hospital for Sick Children, Great Ormond Street in $1983 .^{1}$ The clinical features have recently been redescribed in a paper from the splendidly named Children's Hospital of The King's Daughters in Norfolk, Virginia (Chaves-Carballo et al, American fournal of Diseases of Children 1990; 144: 1079-82). They list nine diagnostic criteria: (1) age less than 10 months, (2) abrupt onset of encephalopathy, (3) fever $\left(39^{\circ} \mathrm{C}\right.$ or more), (4) shock (blood pressure less than $50 \mathrm{~mm} \mathrm{Hg}$ ), (5) disseminated intravascular coagulation, (6) high transaminase, (7) normal blood ammonia, (8) renal dysfunction, and, (9) exclusion of septic shock, toxic shock syndrome, Reye's syndrome, and haemolytic uraemic syndrome.

There may be a prodromal period of several days with vomiting, fever, symptoms of upper respiratory infection, or diarrhoea. The prognosis is awful. Almost all the children have either died or been left with severe neurological impairment. Corrigan in an editorial in the same issue of the journal takes up a point made repeatedly by Bacon in emphasising the importance of fever and the possible relevance of overheating in this syndrome and calls for a change of name to hyperpyrexia, shock, and encephalopathy syndrome. (Calls for a change of name, however worthy, rarely work and often confuse- - unless you're a microbiologist when they both work and confuse.) Similarities between this syndrome and malignant hyperthermia lead to the thought that there could be an underlying metabolic myopathy as yet undefined. In this context it is interesting that a child in the Virginian series who was treated with a muscle relaxant had apparently less severe neurological sequelae.

We're still groping in the dark with this one. The children are desperately ill from the onset and conventional intensive care measures do nothing to lighten the gloom. First understand and then prevent seems the only approach likely to produce dividends.

ARCHIVIST 